\title{
Empirical Study on the Recognition of Critical Factors for Implementing Six Sigma in Taiwan
}

\author{
Jung Lang Cheng \\ Department of Industrial Engineering and Management, \\ College of Engineering, Cheng Shiu University, Taiwan \\ No 840, ChengChin Rd., Niasosong, Kaohsiung, Taiwan \\ Tel: 886-7-731-0606-3523Ｅ-mail: Chengll@gcloud.csu.edu.tw
}

Received: September 18, 2017 Accepted: October 5, 2017

doi:10.5296/ber.v7i2.12084 URL: https://doi.org/10.5296/ber.v7i2.12084

\begin{abstract}
Organizational culture and perceptions regarding systems such as Six Sigma differ among the managers in local enterprises. These differences need to be surveyed based on the concepts underlying the managers' recognition and original meaning of the Six Sigma system, with the goal of creating unique Six Sigma characteristics suitable for local enterprises.Some managers are part-time students pursuing an MBA or EMBA program, and are likely to have an in-depth understanding of Six Sigma. This study applies a questionnaire survey to managers in regard to their perceptions of Six Sigma in Taiwan, conducts an analysis and then offers suggestions based on the results.

The study samples are 300 managers from EMBA or MBA programs in Taiwanese universities. Using SPSS statistical tools, this paper finds that significant difference in Six Sigma implementations among the managers, but some significant differences in organizational characteristics such as industrial characteristics, capital in business scale and the pressure from customers and competitors.
\end{abstract}

Keywords: Six Sigma, Total Quality Management

\section{Introduction}

World-class transnational enterprises like Motorola, GE, and CitiGroup have achieved improved business performance and customer satisfactionby using Six Sigma (Hoerl, Rodebaugh and Snee, 2004; Rucker, 2000). Six Sigma concepts include a top-down approach and a disciplined and highly quantitative method for improving product or process quality, with data-oriented customer-focused measurements used to drive continuous improvement at 
all levels with total employee involvement under the Six Sigma system (Hahn and Doganaksoy, 2000).

Some local enterprises in Taiwan have also been following the Six Sigma system. However, organizational culture and perceptions regarding such systems differ among the managers in local enterprises. These differences need to be surveyed based on the conceptsunderlying the managers' recognition and the original meaning of the Six Sigma system, withthegoal of creating unique Six Sigma characteristics suitable for local enterprises.

This study aims to survey the critical factors and considerationsof Six Sigma implementation which can be applied to domestic enterprises in Taiwan. In order to do this, a research structure and a questionnaire surveywere developed. Based on the questionnaire results, suggestions are offered to the managers in both local and transnational enterprises.Consequently, the purposes of this article are as follows:

1.1 The paper first aims to understand the critical factors for enterprises implementing Six Sigma in Taiwan.

1.2This study applies a questionnaire survey to managersin regard to their perceptions of Six Sigma in Taiwan, conducts an analysis and then makes suggestions based on the results.

1.3 Based on the concepts underlying the managers' considerations and the original meaning, of the Six Sigma system, unique Six Sigma implementationcharacteristics suitable for organizations areestablished.

\section{Critical Factors in Implementing Six Sigma}

Six Sigma's long-term goals are to develop and implement processes within administrative or service activitieswhich lead to business excellence and customer satisfaction. The method was successfully applied at AlliedSignal, General Electric, and Motorola. GE CEO Jack Welch even claimed that Six Sigma had become part of GE's DNA (Hendrick and Kelbaugh, 1998). Smith and Blakeslee (2002) analyzed firms thathad applied the Six Sigma approach, not only to their manufacturing processes, but also to their research, customer service, and other functions. The Six Sigma System is widely acknowledged as possessing the ability of increase market share, drive costs down and increase profit margins. Critical factors inimplementing Six Sigma are considered via a literatures review, as follows.

\subsection{Top Management Determination and Involvement}

The first commandment of Six Sigma quality is that you must get top management commitment in order to succeed (Arthur, 2003). Six Sigma initiativesare driven by leaders at the highest levels of organizations, such as Jack Welch at GE, who strongly influenced and enabled the restructuring of the business organization and changed the attitude of employees towards Six Sigma (McFadden, 1993; Henderson and Evans, 2000).

\subsection{Cultural Changes}

Six Sigma initiatives are also necessary in order to change organizational culture, and plan a course toreview old organizational concepts (Trompenaarsand Hampden-Turner, 1998). In a 
management context and from a strategic perspective to implement Six Sigma alternatives, it is necessary to translate quality concepts into the context of the organizational culture, such as a training program that accounts for cultural differences and local organizational culture (Kenett andAlbert,2001).

\subsection{Managerial Elements}

Six Sigma has evolved from scientific management and continuous improvement theories by combining the finest managerial elements of many former quality initiatives as its methodology and tools to fit organizations' own operations (Aboelmaged, 2010). Six Sigma is an organized and systematic method for strategic process improvement and new product and service development; it relies on statistical methods and the scientific method to make dramatic reductions in customer defined defect rates (Lindermanet al. 2003).

\subsection{IntegratingManagement}

ASix Sigma project must have a direct impact on both financial and operational goals, and is more a business philosophy than just a few tools and techniques (Bunuel and Antony, 2002).Six Sigma's power comes from its integration of the team based approach, customer orientation, financial motivation and assessment, tangible rewards for success, qualitative and statistical tools, and a focus on short duration, high impact projects(Nachtsheim, 2003). The management level must therefore commit to providing opportunities and incentives for the involvement ofall employees for creating the desired results of business management.

\subsection{Business Strategy}

Six Sigma as a strategy differs from other conventional improvement programs in itsfocus on establishing relationships among business $\mathrm{Y}$, customer $\mathrm{Y}$, process $\mathrm{Y}$, and inputs(Xs)(Kapadia, Hemanth and Sharda, 2003) The focus of Six Sigma project quality improvement is the root-analysis of defects in the process of problem analysis and generating solutions. Effective project management is essential for achieving the success of any Six Sigma project; this consists of planning, management, accountability, and the Champion's ability to select, prioritize the scope, andremove barriers for Six Sigma Black Belt projects (Lynch, 2003).

\section{Research Methodology}

The research framework (Figure 1)consists of the critical factors in implementing Six Sigma, other considerations of Six Sigma implementation, and descriptions of the samples.With regard to Six Sigma implementation, this paper will explore its relationship with the following:

3.1Main promotion department: Which main department will push Six Sigma activities?

3.2 Promotion motives: What are the reasons for pushing Six Sigma activities in the organization?

3.3 Implementation schedule: What isthe thinking about scheduling the implementation of Six Sigma? 


\section{Macrothink}

Business and Economic Research

ISSN 2162-4860

2017, Vol. 7, No. 2

3.4 Decision-maker: Who is the main decision-maker for deciding toimplement Six Sigma?

3.5 Implementing problems: What problems are of the greatest concernin implementing Six Sigma?

3.6 Implementation budgets: What budget is acceptable for implementing Six Sigma?

3.7 Training schedule: What is the schedule for training Six Sigma education?

3.8 Quality management activities: What quality activities have been implemented before pushing Six Sigma?

3.9 Improvement items: What items expect the most improvement after implementing Six Sigma?

3.10 Hindrances to implementation: What are the main difficulties in implementing Six Sigma?

Respondents were required to indicate their level of agreement and disagreement with the "Execution degree" of each statement (which measured the practical implementation of Six Sigma management). A five-point Likert scale ( $1=$ strongly disagree, $5=$ strongly degree) was used to gather data on Six Sigma implementation based on attitude-related statements. Using SPSS 17.0 statistical skills, the statistical approaches included sample descriptions, t-test, ANOVA analysis and Pearson correlation.

Our samples are MBA or Executive-MBA (EMBA) students in Taiwanese universities. Many managers in Taiwan are facing global competition and productivity pressures. They need to upgrade their competence; thus, many Taiwanese universities have opened MBA or EMBA programs to meet these needs. The managers must hold a management position if they want to study in any ofthe MBA or EMAB programs in Taiwanese universities. Being managers, the students will know the current and situational quality activities of their organizations.

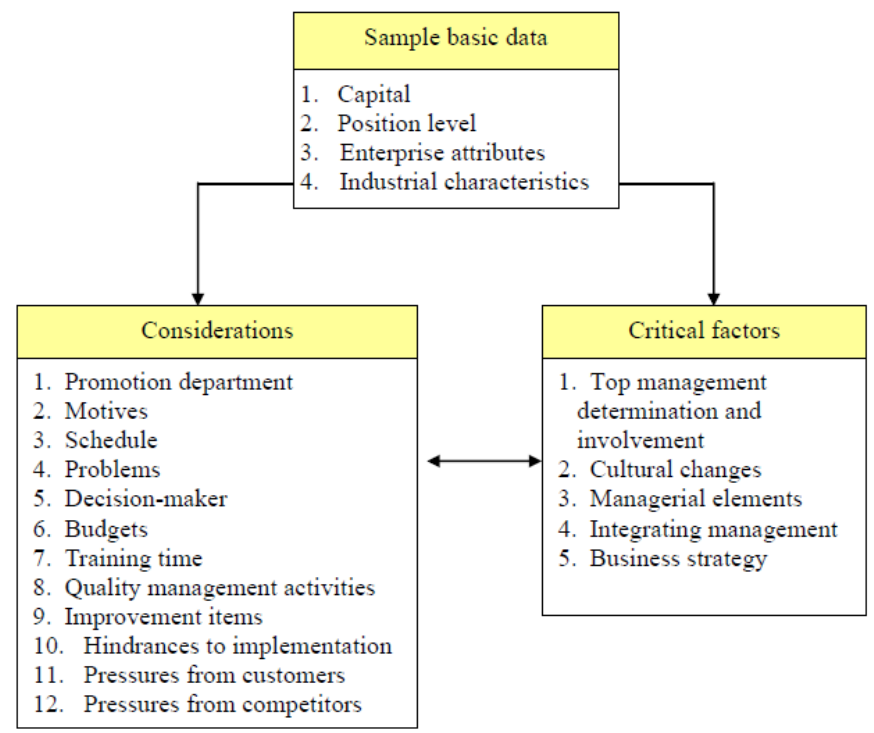

Figure 1. Research framework 


\section{Research Results and Discovery}

The sample selected comprised 300 managers who were EMBA or MBA students at universities in Taiwan; 242 questionnaires were retrieved, and the final number of usable responses was 209 , that is, the rate of recovery for the questionnaires was $80.6 \%$ (242 retrieved samples/300 total samples) and the rate for usable questionnaires was $69.6 \%$ (209 effective samples/300 total samples). The analysis data include sample descriptions, the considerations of Six Sigma implementation, the recognitions of critical success factors and hypotheses testing.Table 1shows the sample descriptions,includingthe capital scale, management position level, enterprise attributes and industry characteristics.

Table 1. Sample characteristics

\begin{tabular}{|c|c|c|c|}
\hline Clarified & Items & Samples & Percent \\
\hline \multirow{4}{*}{$\begin{array}{l}\text { Capital } \\
\text { (The exchange rate is based } \\
\text { on US\$ } 1: 30 \text { NT\$) }\end{array}$} & Below NT\$20 million & 20 & $9.6 \%$ \\
\hline & NT\$2 20.01 million to 40 million & 14 & $6.7 \%$ \\
\hline & NT\$ 40,01 million to 60 million & 9 & $4.3 \%$ \\
\hline & NT\$ 60.01 million to 80 million & 8 & $3.8 \%$ \\
\hline \multirow[t]{2}{*}{ Management position } & High managers & 77 & $36.8 \%$ \\
\hline & Medium managers & 132 & $63.2 \%$ \\
\hline \multirow[t]{2}{*}{ Enterprise attributes } & Publicly-owned enterprise & 46 & $22 \%$ \\
\hline & Private enterprise & 163 & $78 \%$ \\
\hline \multirow[t]{13}{*}{ Industry characteristics } & Electronics and electronic machinery & 24 & $11.5 \%$ \\
\hline & Steel-and-metal & 30 & $14.4 \%$ \\
\hline & Textiles & 2 & $1 \%$ \\
\hline & Internet & 5 & $2.4 \%$ \\
\hline & Neurochemistry & 13 & $6.2 \%$ \\
\hline & Mechanical & 11 & $5.3 \%$ \\
\hline & Electronics & 3 & $1.4 \%$ \\
\hline & Semi-conductors & 14 & $6.7 \%$ \\
\hline & Food-and-medicine & 25 & $12 \%$ \\
\hline & Information Technology & 6 & $2.9 \%$ \\
\hline & Finance and Insurance & 29 & $13.9 \%$ \\
\hline & Construction & 13 & $6.2 \%$ \\
\hline & Others & 34 & $16.3 \%$ \\
\hline
\end{tabular}

\subsection{The Main Six Sigma Promotion Department}

The main person responsiblefor implementing Six Sigma is the CEO or General Manager (63\%), whilea significant percentage of samples (26.3\%) think that implementing Six Sigma may be just the responsibility of department managers or staff. The data show that implementing Six Sigma is a top-down process, which is consistentwiththe literature reviews.

\subsection{The Motives for Implementing Six Sigma}

The main motives for implementing Six Sigma are "Requirement of self-enhancement" 
(71.8\%), and "Upgrade corporate image" (23.4\%). Most firms agree that implementing Six Sigma has benefits that canimprove competitiveness and the corporate image.

\subsection{The Schedule for Implementing Six Sigma}

$50.2 \%$ of firms have not implemented Six Sigma or prepared to implement Six Sigma. $7.7 \%$ of firms think that Six Sigma is not suited to their organizational cultures, while $42.1 \%$ are not still clear on how to decide ona their future quality management system. The data shows that the main priority in Taiwan is helping the firms better understand what Six Sigmais and what it can achieve.

\subsection{Decision-maker forImplementing Six Sigma}

The main decision-makersfor implementing Six Sigma are the owner $(56.0 \%)$, the department staffers $(17.7 \%)$ and the manager $(11.5 \%)$.

\subsection{The Problems with Implementing Six Sigma}

The reported problems with implementing Six Sigma are: "Organizational culture shock"(23.9\%), "Expected results are not very clear"(18.7\%), "The overload of human resourceswith Six Sigma related work"(13.4\%), "The degree to which Six Sigma is accepted in the organization" (13.4\%), "It is the same system as the current TQM activities"(8.1\%), "The conflicts with organizational culture", $(7.7 \%)$, "The inadequacy of employee learning ability" $(7.2 \%)$ and "Issuesrelated to the implementation budgets" $(6.2 \%)$. The data show that the problem of most concernisto what degree implementing Six Sigma will influence the current quality management activities. In addition, the firms also worried about how Six Sigma activitieswould affectbusiness performance.

\subsection{The Budgets for Implementing Six Sigma}

The budgets for implementing Six Sigma are base on expressed in New Taiwanese dollars (NT\$). The exchange rate for US\$ are based on 1US\$=30 NT\$. The distribution range of the acceptable budget for implementing Six Sigma followsa smooth curve.According to respondents, the most acceptable, in descending order of popularity, is NT\$500 thousand to 1million (27.8\%), below NT\$ 300 thousand (15.8\%), 300 thousand to500 thousand NT\$ (19.6\%), NT\$1.1 million to 3.0 million (18.2\%), NT\$ 3.1 million to 5.0 million NT\$ $(8.1 \%)$ and above 5.0 million (10.5\%). The exchange rate for US\% are based on $1 \mathrm{US} \$=30 \mathrm{NT} \$$

\subsection{Six Sigma Training Schedule}

Most of the firms use some work and non-work hours to conduct Six Sigma education and training $(54.1 \%)$, but some firms $(34.9 \%)$ are willing to use only work hours for this.

\subsection{Quality Management Activities that have beenImplemented}

Figure 2 shows that $84.7 \%$ of firms have implemented the ISO9000 quality system, $43.1 \%$ TQM, $37.7 \%$ quality control circle activities (QCC), and $36.4 \%$ the ISO14000 system. The lowest value wasfor statistical process control (SPC), at $17.7 \%$, meaning that the firms 
must strengthen their statistical skills and activities in order to successfully implement Six Sigma.

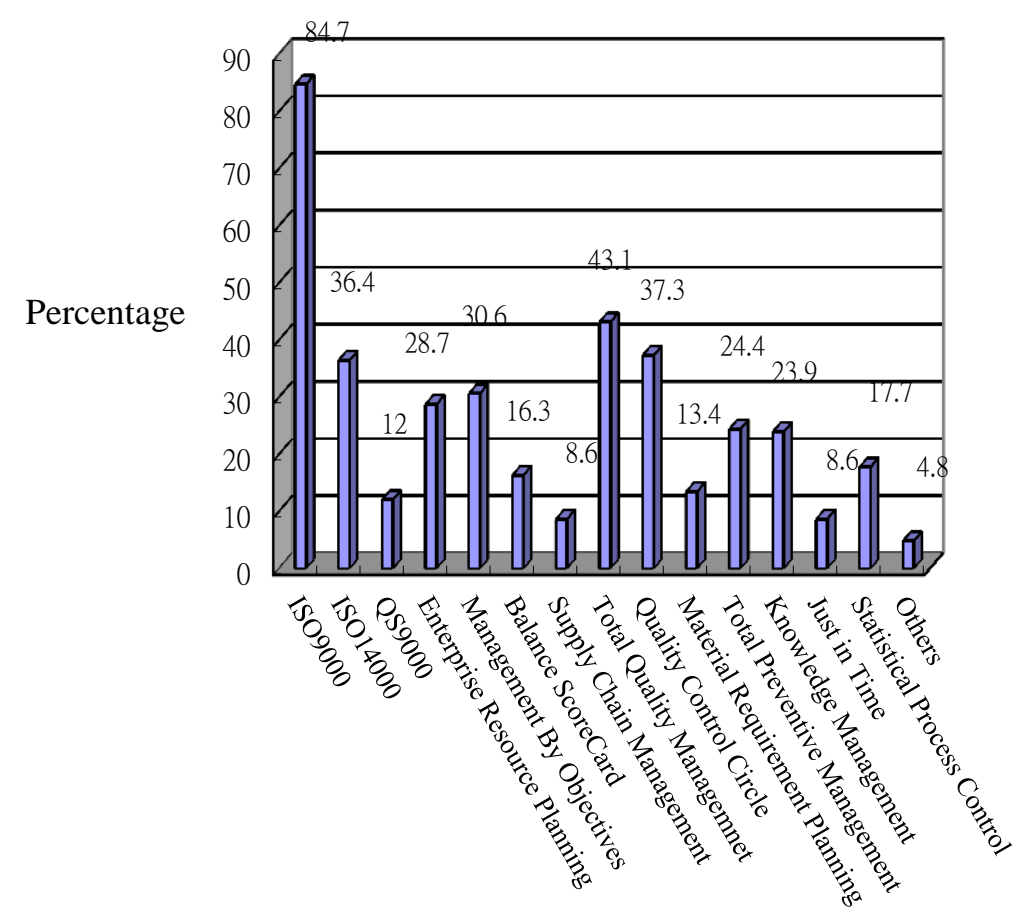

Figure 2. Other quality management activities undertaken by the firms

\subsection{The Most Expected Improvement Item after Implementing Six Sigma}

The items withthe most expected improvement are "Customer satisfaction" (65.1\%), "Yield" (54.1\%), and "Cost" (45\%) (See Figure 3).

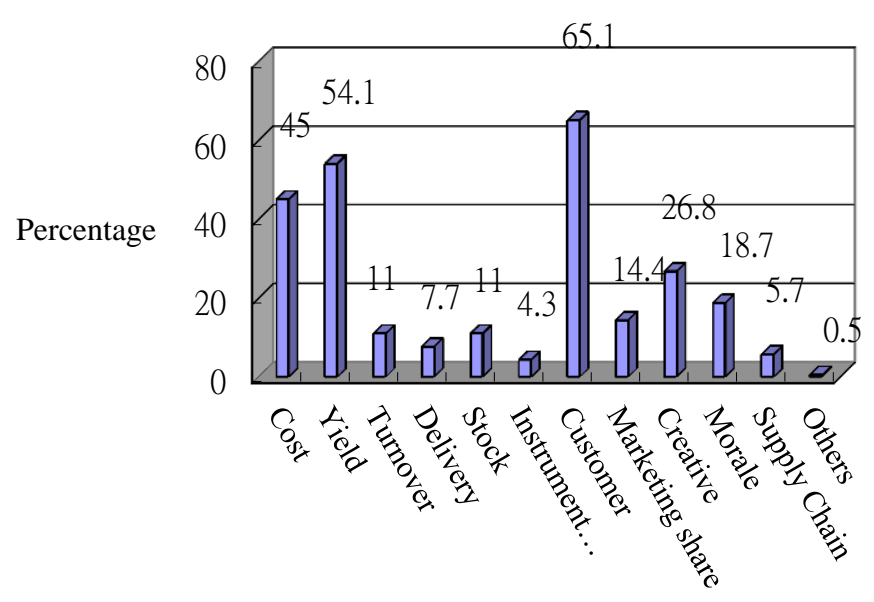

Figure 3.Items with the most expected improvement 


\section{Macrothink}

\subsection{The Hindrancesin Implementing Six Sigma (Alternative choices)}

The main hindrancesin implementing Six Sigma are "Inadequate coordination of employees" (54.5\%), "Recognition bias of top manager" (39.2\%), "Insufficient Six Sigma professional knowledge" (38.8 \%) and "Top managers do not emphasize Six Sigma" (37.3 \%). Therefore managersmust build employee coordination and integrationbefore and while implementing Six Sigma

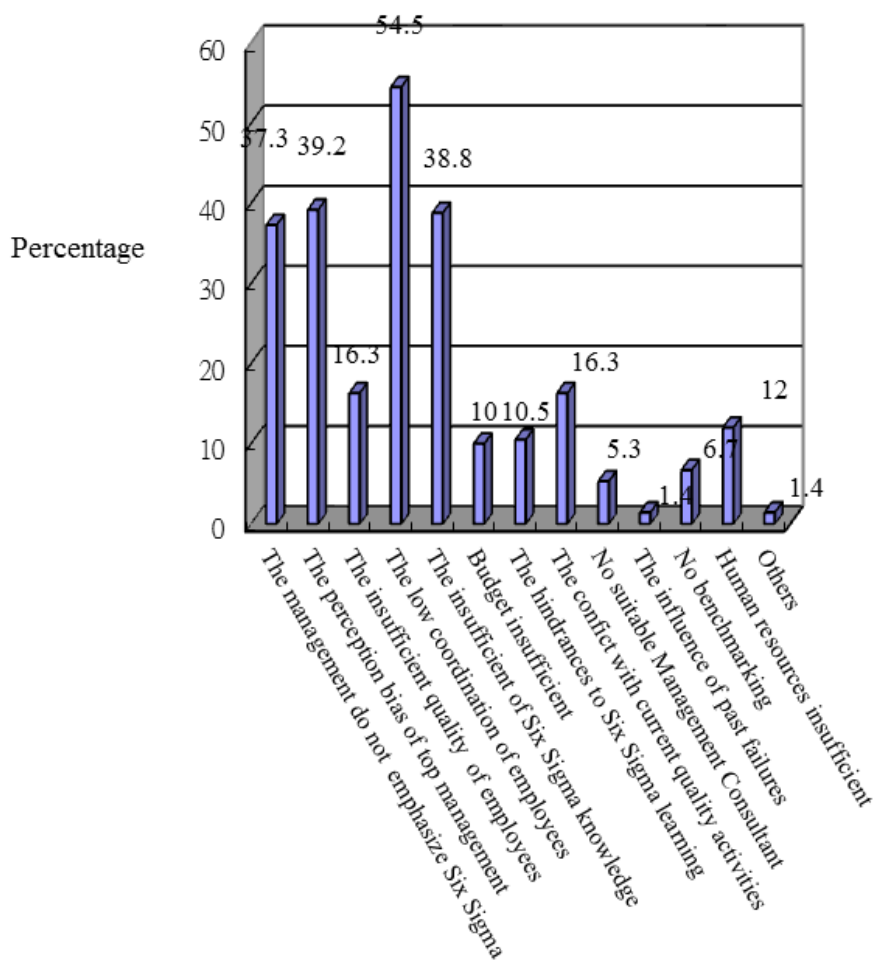

Figure 4. The hindrances of implementing Six Sigma

\section{Conclusions and Management Implications}

\subsection{Conclusion}

\subsubsection{The Implementing Six Sigma Schedule}

OF the firms studied, 50.2\%that have not implemented or are prepared to implement Six Sigma, and $42.1 \%$ are considering what to do, when to start and how to implement the Six Sigma activities, but $7.7 \%$ thought that the Six Sigma does not suit their enterprise characteristics. The managers believe that the main staff to promote the Six Sigma system is the CEO or General Manager (63\%), which demonstrates a top-down approach. A slight majority of the firms feel that determining whether toimplement Six Sigma should be the owner's decision $(56.0 \%)$.

\subsubsection{The Expectations Range of Acceptable Budgets to Implement Six Sigma}

The range of acceptable budgets to implement Six Sigma follow a normal distribution, and the most acceptable budgets are from NT $\$ 500$ thousand to one million $(27.8 \%)$. The budgets of implementing Six Sigma are not very high. The data shows that the firms in Taiwan 
implement Six Sigma by themselves, and that the time Six Sigma used for training and education includes both work hours and non-work hours (54.1\%), while $34.9 \%$ of firms accept that Six Sigma education should be totally arranged during work hours.

\subsubsection{The Motives and Quality Activities for Implementing Six Sigma}

The managersagree that Six Sigma activities have benefited business management $(71.8 \%)$ and upgraded the corporate image (23.4\%). The data show that the value of Six Sigma has been confirmed by the managers in Taiwan. The most common expected improvements are customer satisfaction $(65.1 \%)$, yield $(54.1 \%)$ and cost $(45 \%)$.

Most firms have implemented the ISO9000 system (84.7 percent), followed by TQM (43.1\%), QCC improvement activities (37.3\%) and ISO14000 system (36.4\%), while only $17.7 \%$ are using SPC tools. The data show that the statistical skills and basic quality activities are critical elements that must be taught to staff before Six Sigma is implemented.

\subsubsection{The Obstacles and Problems before Implementing Six Sigma}

The main obstacles for Six Sigma implementation include the following: the managers are deeply concerned about employee attitude towardthe implementation(54.5\%), Six Sigma recognition bias of $\mathrm{t}$ thetop managers $(39.2 \%)$ and that top managers do not emphasize Six Sigma " (37.3\%). The firms shouldpromote business reengineering and Six Sigma training. The problem that most concerns firms is to what degree implementing Six Sigma will influence the current quality management activities(23.9\%). They are also worried about the effectiveness of Six Sigma performance (18.7\%).

\subsection{Management Implications}

5.2.1 If the firms can master these critical factors while implementing Six Sigma, they will experience improvedbusiness performance. The key critical factors for implementing Six Sigma in this paper are the determination and decision of top management, cultural change, resource allocation, and integrating management and business strategy.

5.2.2 This paper finds no significant differences among the managers but some significant differences in organizational characteristics, such as industrial characteristics, capitalrelated to business scale and pressure from customers and competitors. To avoid inconsistent recognition for implementing Six Sigma, firms shouldnot only adopt top-down approaches, but also pay attention to a more general integration of Six Sigma concepts and the attitudes of employees.

\section{References}

Aboelmaged. M. G. (2010). Six Sigmaquality: a structured review and implications for future research, The International Journal of Quality \& Reliability Management, 27(3), 269-318.https://doi.org/10.1108/02656711011023294

Arthur, J. (2005).Seduce them with success, Quality Progress,38(9), 35-40.

Bunuel, C. R., \& Antony, J. (2002).Critical success factors for the successful implementation 
of Six Sigma projects in organizations, The TQM Magazine, 14(2), 92-99.

https://doi.org/10.1108/09544780210416702

Hahn, G. J., \& Doganaksoy, N. (2000).The evolution of Six Sigma, Quality Engineering, 12(3),317-326. https://doi.org/10.1080/08982110008962595

Henderson, K. M., \& Evans, J. R. (2000). Successful implementation of Six Sigma: benchmarking General Electric Company, Benchmarking: an International Journal, 7(4), 260-81.

Hendricks, C. A., \& Kelbaugh, R.L. (1998).Implementing six sigma at GE,Journal for Quality and Participation, 21(4), 48-54.

Hoerl, R.W., Rodebaugh, W., \& Snee, R. D. (2004). Six Sigma and statistical leadership, ASQ's Annual Quality Congress Proceedings.385-390.

Kapadia, M. M. S., \& Hemanth, B. Sharda. (2003). Six Sigma: the critical link between process improvements and business results, www.sixsigmaforum.com Oct. 13, 2003

Kenett, R. S., \& Albert, D. (2001).The international quality, Quality Progress, 34(7), 45-51.

Linderman, K., Schroeder, R. G., Zaheer, S., \& Choo, A.S. (2003). Six Sigma: a goal-theoretic perspective, Journal of Operations Management, 21(2), 193-203.

https://doi.org/10.1016/S0272-6963 (02)00087-6

Lynch, D. P. (2003).Five steps to success, ASQ Six Sigma Forum Magazine, 2(2), 27-33.

McFadden, F. R. (1993). Six-Sigma quality program, Quality Progress, 26(6), 37-41.

Nachtsheim, C. 1. (2003). A powerful analytical tool, Six Sigma Forum Magazine, 2(4), 28-35.

Rucker, R. (2000).Citibank increases customer loyalty with defect-free processes, Journal for Quality and Participation, 23(4), 32-37.

Smith, D., \& Blakeslee, J. (2002). The new strategic Six Sigma, T+D, 56(9), 45-52.

Trompenaars, F., \& Hampden-Turner, C. (1998).Riding the Waves of Culture, New York, McGraw-Hill.

\section{Copyright Disclaimer}

Copyright for this article is retained by the author(s), with first publication rights granted to the journal.

This is an open-access article distributed under the terms and conditions of the Creative Commons Attribution license (http://creativecommons.org/licenses/by/3.0/). 